\title{
Informing a Different Conversation About Medication
}

Ann Fam Med 2016;14(5):iii. doi:10.1370/afm.1984.

The Annals of Family Medicine encourages readers to develop a learning community of those seeking to improve health care and health through enhanced primary care. You can participate by conducting a RADICAL journal club and sharing the results of your discussions in the Annals online discussion for the featured articles. RADICAL is an acronym for Read, Ask, Discuss, Inquire, Collaborate, Act, and Learn. The word radical also indicates the need to engage diverse participants in thinking critically about important issues affecting primary care and then acting on those discussions. ${ }^{1}$

\section{HOW IT WORKS}

In each issue, the Annals selects an article or articles and provides discussion tips and questions. We encourage you to take a RADICAL approach to these materials and to post a summary of your conversation in our online discussion. (Open the article online and click on "TRACK Comments: Submit a response.") You can find discussion questions and more information online at: http://www.AnnFamMed.org/AJC/.

\section{CURRENT SELECTION}

\section{Article for Discussion}

Sidorkiewicz S, Tran V, Cousyn C, Perrodeau E, Ravaud P. Discordance between drug adherence as reported by patients and drug importance as assessed by physicians. Ann Fam Med. 2016;14(5):415-421.

\section{Discussion Tips}

This article provides an unusual opportunity to consider patients' understanding and use of their medications-to consider and convey the relative importance of patients' drugs from a medical point of view, to ask carefully about, rather than assuming, which drugs people are taking and why, and perhaps to work toward shared understanding.

\section{Discussion Questions}

- What question is asked by this study and why does it matter?

- How does this study advance beyond previous research and clinical practice on this topic?
- How strong is the study design for answering the question?

- To what degree can the findings be accounted for by: 1. How participating physicians and patients were selected?

2. How the main variables were measured?

3. Confounding (false attribution of causality because 2 variables discovered to be associated actually are associated with a 3 rd factor)?

4. Chance?

5. How the findings were interpreted?

- What are the main study findings - among patients, among physicians, and particularly around their comparison? (See additional findings in the online appendix.)

- How comparable is the study sample to similar patients in your practice? What is your judgment about the transportability of the findings? How does the mix of inpatient and outpatient samples affect your interpretation of the findings?

- What contextual factors are important for interpreting the findings?

- How might this study change your practice? Policy? Education? Research?

- What different conversations might we have to understand what we now are assuming? Or to share our priorities from a medical point of view and listen to patient's point of view as they live their lives and try to integrate pharmacotherapy? How might we find the sweet spot between these perspectives, and in the process, develop healing relationships that can be called on for issues beyond drug treatment?

- Who the constituencies are for the findings, and how they might be engaged in interpreting or using the findings?

- What are the next steps in interpreting or applying the findings?

- What researchable questions remain?

\section{References}

1. Stange KC, Miller WL, McLellan LA, et al. Annals Journal Club: It's time to get RADICAL. Ann Fam Med. 2006;4(3):196-197. http:// annfammed.org/cgi/content/full/4/3/196. 